\title{
Suggestions on Innovative Design of Hakka Needlecraft arts and Cultural Creative Products
}

\author{
LAI Wenqing ${ }^{1}$ \\ ${ }^{1}$ College of Applied Science, Jiangxi University of Science and Technology ,Ganzhou 341000,China
}

\begin{abstract}
In recent years, the tourism industry in southern Jiangxi, which focuses on Hakka elements, is developing rapidly with a strong momentum. Hakka culture is one of the keywords of the tourism image in southern Jiangxi. The traditional Hakka needlecraft culture in southern Jiangxi is an integral part of Hakka culture. As a tourism creative industry, the traditional Hakka needlecraft culture in southern Jiangxi is regarded as a kind of afterwork. The cultural value of the industry era is affirmed, and its economic value has changed greatly. Thesand gained a new economic basis. Their value orientation is no longer the situation of "good quality and low price", but because they are rich in humanistic value, emotional value and local characteristics. e female red cultural creative products have been re-recognized through the economic value of tourism development, And get "value for money" brand positioning, this culture has an irreplaceable role in promoting the economy, has great economic value. Compared with the "hard power" of politics and economy, culture is a "soft power", and its influence and penetration to economy and society are continuous. Hakka needlecraft culture is a treasure of folk art in Jiangxi and even the whole Hakka family. As one of the "soft power" of culture, folk craft has the value of promoting local economic development.
\end{abstract}

\section{Introduction}

"One side of water and soil supports one person", and one side of soil and water nourishes a culture. If you say "the formation of Hakka culture, it means the formation of its carrier-Hakka folk lineage" ${ }^{[1]}$. Folk art is an important part of the rich culture created by Hakka people. Because these folk arts are the creations of ordinary people in their daily lives, they also vividly reflect the folk customs and feelings of this region. As the folk art scientist Mr. Zhang Daoyi thinks: "Folk art is connected with the spirit of the majority of laborers, directly showing their love, ideals, psychology, aesthetic taste, etc., so it seems straightforward, simple, and has a distinct rustic flavor"[2]. Among the colorful folk arts, Hakka female red art clearly shows the spiritual world of Hakka women. As a distinctive cultural and creative derivative design in Hakka, it must first conform to the cultural connotation of Hakka female red: craftsmanship and female red culture, which fully reflects the spirit and artistic appeal of traditional female red culture. Cultural creative derivative design can be based on The female red IP image is creative, designed many products that meet the needs of people's lives, and combined with the female red element innovative design to transform traditional culture into cultural products that can be used and conform to the people's aesthetics, enhance the market competitiveness of products, and make them mutually Integration, mutual influence, enhance cultural self-confidence and influence.

\section{Hakka female red status}

The protection and inheritance of regional culture is an important part of the current cultural world, and the cultural and creative industry has become a hot industry in the world in recent years, and its cultural and creative products have also won the favor and attention of consumers. In this process, there is always a pair of associated but contradictory problems: on the one hand, how to adapt these unique non-heritage projects formed in specific traditional communities and traditional folk customs to the needs of contemporary life and realize their Economic benefits, embarked on a path of industrialization, thereby promoting its inheritance and development; on the other hand, how to make these nonheritage projects that used to be in the form of folklore maintain their own culture, region and national characteristics, and maintain their differences On the basis of, it is reasonably transformed into products and services, and enhances the cultural identity of non-legacy holders, rather than completely stripping it from the folk environment and alienating it into a symbol in a consumer society ${ }^{[3]}$.

Before the word "female red" appeared, it means that women are engaged in embroidery, sewing, textile and other related tasks. There are "Female Gong", see "Zhou Li - Diguan · Chang": "Tend it to work hard, check its female Gong." Zheng Xuan's note: "Female Gong, Si 
Ma." There is "Female Red", "Han "Book·Jingdi Ji" has Zhao Yun: "Glyphs are engraved and engraved, which hurts the farmer's people; the splendid embroidered group, and those who harm the female red." and so on. Among these words, "Female Red" is still active in our speech. Female red art is a kind of art that originates from practicality and is highly skilled. In an era of scarce resources, women completed their clothes from head to toe with the needles in their hands, the hemp they planted, and the threads they spun. It can be seen how skillful and painstaking they are, and the female representative is the most representative Sexual craftsmanship is embroidery. In the eyes of Hakka women, a beautiful needlecraft is the greatest happiness in life, so most of the farming time, Hakka women are wearing various patterns with one stitch and one thread. On clothes, shoes and hats. Over time, with the change of the public's aesthetic, traditional Hakka embroidery has faded in our lives. Everyone no longer has the habit of wearing hats and embroidery of Hakka clothing, and the traditional embroidery process is both timeconsuming and non-economically beneficial There are no more people interested in it, and there are very few folk artists who can fully master the Hakka embroidery handicrafts.

In the current work of the protection and inheritance of intangible cultural heritage, productive protection has become a way of introducing traditional non-legacy resources into contemporary social life and industrial systems so that they can be protected "live" in production activities that create social wealth The effective way is increasingly recognized by people. Especially in remote areas where some traditional cultural customs are wellpreserved and economically underdeveloped, the "productive protection" of non-legacy projects with a broad public base is often combined with local industrial economic development plans to become a tradition of revival Community, an important means of developing local economy.

\section{Design Elements of Hakka Female Red Literature Creation}

Design is the driving force to promote cultural development, which not only adds value to culture but also creates the core value of products ${ }^{[4]}$. The research focuses on Hakka female red cultural creativity, Hakka female red cultural and creative concept design, innovative design and application, shaping Hakka female red cultural and creative brand IP, as the main research content. And through the achievements of college students' double innovation training program and the Jiangxi South Hakka Culture Digitalization Institute on the cultural and creative product development results of the Ganxian District Women's Red Association, Hakka women's red cultural and creative product innovation design, and Hakka women's red cultural creative product brand design strategy. The process of using the product is the consumer's interpretation process, which is to interpret the product form, symbolic features and connotation, and enter the meaning symbol hidden behind the surface annotations, thereby completing the transition from clear practical functions to subtle cultural accumulation ${ }^{[5]}$. As a combination of culture and economy, the research on product innovation design strategy of Hakka female cultural and creative industries must focus on creative production and application. The most critical elements are creative management, brand building, and cultural and creative product development and design. Provide strong support in teaching and scientific research.

The research on countermeasures for innovative design of Hakka female art and cultural creative products can be roughly divided into: visual cultural and creative product design, female red cultural and creative IP image design, and two main categories of physical display parts. Among them, the visual literary and creative product design and the IP image design are gradual and interdependent causal philosophical relationship, which is also the focus and difficulty of this topic.

\subsection{Hakka Female Red Culture IP Image Design- Mascot image condensing Hakka female red culture characteristics}

The basic conceptual design of the image is based on the characteristics of female red culture: strong sense of family responsibility, dedication, hard work, feminization, affinity, bigfoot, pragmatism and other concepts. And through the anthropomorphic design method for character design. The cartoon image combines regional features to design derivatives, integrates natural landscapes, cultural landscapes, life scenes, festival sacrifices and other elements to create a distinctive IP feature and build the Hakka female red brand concept and soft cultural strength of cultural and creative products. The basic part of IP integrates the concept of image into the entire image recognition system through family image as an auxiliary and life story as a link.

\subsection{Hakka female red cultural creative products- daily necessities, toys, gifts}

The Hakka female red cultural creative products visual products are the traditional Hakka female red with hats, apparel, insoles and other traditional patterns that have auspicious celebrations and a better vision for life, and good wishes for connotation, such as: "Fu, Lu, Shou, Xi" Letters, "Dragon, Phoenix, Unicorn, Lion and Tiger" animals and "Lotus, Peony, Orchid, Chrysanthemum" flowers, "Lotus, Pomegranate, Peach, Peanut" fruits, "Butterfly, Bird, Dragonfly, Bee" insects and birds and other patterns, Through the form of symmetry, balance, rhythm, rhythm and other beautiful forms of law, and scattered, divergent, polycentric and other forms of formation of scarves, handbags, coin purses, pillows, coasters, key chains, travel badges patterns Design; At the same time, the design is applied with strong contrasting folk colors such as red, blue, yellow and green, which are representative of Hakka traditional 
female red. Such products are distinctive, beautiful, rich in content, magnificent colors, diverse in form, with Strong practical value, easy to decorate and carry tourism creative products.

\subsection{The digital image extension design of traditional Hakka female red culture cartoon illustrations.}

Cultural digital image and animation creative products are accurately developed in accordance with the current mainstream mobile media market needs and functions, and serve to expand the influence of local culture in Jiangxi South. In other words, digital video and animation creative products are an important way to create Hakka female red cultural IP hotspots and to promote and expand the recognition and sales channels of local tourism products in Jiangxi South. Cultural digital image and animation creative products are developed in three categories: one is the digital graphic category such as Hakka themes using digital painting techniques, designed to be cultural postcards, cultural calendars and other paper creative products; the second is the digital image category such as Hakka local cultural documentaries , Micro movies, etc.; the third is digital animation, such as expression packs and serial comic creation and story development with Hakka female red culture as the background. Cultural digital video and animation creative products and traditional physical tourism products have good fashion, broad dissemination and immeasurable value.

\section{Conclusion}

Starting from the IP brand design, by telling good Hakka stories, creating a visual image to pass on to consumers to deliver rich and in-depth Hakka female red stories, it is a breakthrough to enhance the overall image of female red in Hakka areas: shaping the creative taste of Hakka female red cultural IP It is an urgent requirement to enhance the overall image of Hakka female red derivatives and enhance the market competitiveness of products. The development of Hakka tourism products follows this principle, develops IP ideas, and derivatives closely integrated with the theme of Hakka female red culture to form a viable IP brand. This is a good way to enhance the confidence of Hakka culture and realize the globalization of Hakka cultural tourism products Way.

\section{Acknowledgment}

Funding project: 2017 Jiangxi Province Culture and Art Science Planning Project: Phased results of the research on the construction of the Jiangxi Gannan Hakka Huamao Digital Resource Database (No. YG2017065B)

\section{References}

1. Tian Huilong. Artistic characteristics of decorative symbols of Hakka clothing [J]. Packaging Engineering, 2005(26): 184-185, 127.
2. Zhang Haihua. A preliminary study of Hakka child hat culture $[\mathrm{J}]$. Journal of Gannan Normal University: Educational Science Edition, 2014, 36(1): 46-49.

3. Zhang Duoduo, Ji Tie. Collaborative design "touches"the revival of traditional communitiesTaking non-legacy research and innovative practice of the "New Channel-Hua Yao Hua" project as an example[J]. Decoration, 2016(12): 26-29.

4. Zhang Yuping, Lu Han. Research on the design of Qiang cultural products [J]. Packaging Engineering, 2015, 36(4): 125. ZHANG Yu-ping, LUHan. Qiang Cultural Product De-sign [J]. Packaging Engineering, 2015, 36(4): 125.

5. Feng Chongyu. Creative Tools[M]. Shanghai: Shanghai People's Publishing House, 2010. FENG Chong-yu. Creative Tools[M]. Shanghai: Shanghai People's Fine Arts Publishing House, 2010. 